\title{
Regulation of GABA Transporter Activity and mRNA Expression by Estrogen in Rat Preoptic Area
}

\author{
Allan E. Herbison, ${ }^{1}$ Sarah J. Augood, ${ }^{2}$ Sharon X. Simonian, ${ }^{1}$ and Chris Chapman ${ }^{1}$ \\ 'Laboratory of Neuroendocrinology and ${ }^{2} \mathrm{MRC}$ Molecular Neuroscience Group, Department of Neurobiology, The \\ Babraham Institute, Cambridge, CB2 4AT, United Kingdom
}

This study has examined whether estrogen regulates GABA transporter synthesis and activity in the female rat brain. In the first experiment in situ hybridization studies examined the effects of ovariectomy on cellular GABA transporter-1 (GAT-1) mRNA content. A $25 \%$ decrease in GAT-1 mRNA expression was detected within the medial preoptic area (MPOA) but not the parietal cortex, magnocellular preoptic nucleus (Mg-POA) or caudate-putamen (CP). Estrogen replacement for 7 d returned GAT-1 mRNA content of MPOA cells to levels observed in intact rats. In the second experiment, the effect of increased brain GABA concentrations on GAT-1 mRNA expression was investigated by treating rats with $\gamma$-vinyl GABA, a GABA-transaminase inhibitor. Although resulting in a twofold increase in tissue GABA content, in situ hybridization experiments revealed no changes in GAT-1 transcript expression. A third series of experiments examined GABA transporter activity in vitro using a ${ }^{3} \mathrm{H}$ GABA uptake assay in MPOA, cortex, and C-P punches. Nipecotic acid (10 $\mu \mathrm{M})$ reduced specific ${ }^{3} \mathrm{H}$ GABA uptake in all three brain regions while 100 $\mu \mathrm{M} \beta$-alanine only reduced uptake in the MPOA. Estrogen treatment for $7 \mathrm{~d}$ resulted in a significant increase in ${ }^{3} \mathrm{H}$ GABA uptake in the MPOA but not the cortex or C-P. The presence of a putative estrogen response element in the GAT-1 gene and the effects demonstrated here on GAT-1 mRNA content and GABA transporter activity indicate that estrogen may influence GAT-1 gene transcription to alter GABA transporter function within the MPOA but not the C-P or cortex.

[Key words: cerebral cortex, estrogen, GABA, GABA transaminase, GABA transporter, messenger RNA, preoptic area, striatum]

The preoptic area is associated with both hypothalamic and limbic systems and implicated in the control of diverse autonomic and neuroendocrine functions as well as a variety of reproductive bchaviours (Boulant and Dean, 1986; Freeman, 1994; McGinty et al., 1994; Numan, 1994). An important feature of the preoptic area is that it contains one of the largest populations of cells expressing gonadal steroid receptors in the CNS (Pfaff

Received May 31, 1995; revised July 24, 1995; accepted July 28, 1995.

Drs. J. Bicknell, S. Luckman, and D. Voisin are thanked for reviewing an earlier draft of the manuscript and Mr. I. King's assistance with the emulsion autoradiography is gratefully acknowledged. This work was supported in part by MRC Project Grant G9409798N. A.E.H. is a Lister Institute-Jenner Fellow.

Correspondence should be addressed to Dr. Allan E. Herbison at the above address.

Copyright (C) 1995 Society for Neuroscience $0270-6474 / 95 / 158302-08 \$ 05.00 / 0$ and Keiner, 1973; Sar, 1988; Simerly et al., 1990; Herbison and Theodosis, 1992) and, as such, serves as a brain site at which these hormones can modulate neural functioning. In the female rat, in particular, circulating estrogens have been shown to influence both the clcctrical and synthetic activity of proptic neurones (Yagi, 1973; Jones et al., 1988) and, although ill-defined, estrogen actions in this brain region are known to be critical for the regulation of reproduction by the nervous system (Petersen and Barraclough, 1989; Numan, 1994; Pfaff et al., 1994).

The most numerous cell type expressing nuclear estrogen receptors in the preoptic area is that synthesizing gamma aminobutyric acid (GABA); approximately $30 \%$ of preoptic estrogen receptor-containing cells contain glutamic acid decarboxylase (GAD), the synthetic enzyme for GABA (Flugge et al., 1986; Herbison et al., 1993). Studies measuring GABA turnover and extracellular GABA concentrations in the preoptic area have indicated that the estrogen receptors in these GABA neurones are likely to be of functional significance as ovariectomy decreases (Ondo et al., 1982), and estrogen replacement increases (Mansky et al., 1982; Demling et al., 1985; Herbison et al., 1989, 1991), basal and potassium-evoked GABA levels in this area. However, the mechanisms by which estrogen acts on preoptic GABA neurones to influence extracellular GABA concentrations are not known. Gonadal steroids have been reported to regulate GAD synthesis and activity in a variety of brain regions (Wallis and Luttge, 1980; Weiland, 1992; McCarthy et al., 1995), but appear unlikely to regulate $\mathrm{GAD}$ in the female preoptic area as $\mathrm{GAD}_{67}$ mRNA expression (Herbison et al., 1992) and GAD activity (Wallis and Luttge, 1980; O'Conner et al., 1988; Fleischmann et al., 1992) in this region are not influenced directly by ovariectomy or estrogen treatment. Hence, it would appear that the preoptic area provides an example of a brain region where changes in extracellular GABA concentrations may not always be related to GAD activity.

Such observations raise the question of whether gonadal steroids may modulate the other principal determinant of extracellular GABA concentrations, the GABA transporter. Recent molecular cloning studies have identified the presence of three GABA transporters in the rat brain, termed GAT-1, GAT-2, and GAT-3, which exhibit differences in their distribution, pharma-

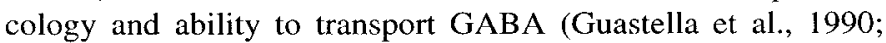
Borden et al., 1992; Clark et al., 1992). However, it is not known whether gonadal steroids may influence GABA transport in the nervous system. In this study we have examined whether estrogen, the principal gonadal steroid of the female, may play a physiological role in regulating GABA transport in the female rat brain by examining the effect of gonadal steroid manipulation 
on both G $\Lambda \mathrm{T}-1$ mRN $\Lambda$ expression and in vitro GABA transporter activity.

\section{Materials and Methods}

Adult female Wistar rats from the Babraham colony were maintained in a light and temperature controlled environment (lights on 05:00-19: $00 \mathrm{hr}, 22^{\circ} \mathrm{C}$ ) with food and water freely available. Metestrous rats were determined by daily vaginal smear and used on the morning of metestrus following two 4 d estrous cycles. All ovariectomies were undertaken on animals anesthetized with Avertin ( $2 \%$ tribromoethanol, $1.0 \mathrm{ml} /$ $100 \mathrm{gm}$ body weight, i.p.) 3-4 weeks prior to experimentation and all procedures were conducted in accordance with Home Office requirements for Animal Scientific Procedures (Project 80/00704).

Experiment 1: effect of ovariectomy and estrogen-replacement on GAT-I mRNA expression. In the first part of this experiment, five ovariectomized rats and five metestrous rats were used. In the second part, undertaken at a later date, three groups of rats were ovariectomized and 3 weeks later given subcutaneous silastic capsule implants (length 14 $\mathrm{mm}$, i.d. 0.062 in., o.d. 0.125 in.; Dow Corning USA). In the first group of rats (OVX; $n=5$ ) implants contained the vehicle ethyl oleate alone while animals in the second group (OVX-E7d; $n=5$ ) received silastic implants filled with a $50 \mu \mathrm{g} 17-\beta$ estradiol $/ \mathrm{ml}$ ethyl oleate solution. Animals were killed $7 \mathrm{~d}$ later. A third group (OVX-E24h; $n-5$ ) received the same estradiol-filled capsule but $24 \mathrm{hr}$ prior to decapitation. Estradiol capsules prepared and administered in this way return plasma estradiol concentrations to physiological levels observed at metestrus within 24h (Leipheimer et al., 1984). All rats were stunned by a blow to the back of the neck and decapitated between 10:00 and 11:00 A.M., their brains removed and frozen on dry ice. Fresh frozen sections $(15$ $\mu \mathrm{m}$ thick) were cut in the coronal plane, thaw mounted onto gelatinized slides and stored at $-70^{\circ} \mathrm{C}$.

An antisense oligonucleotide complementary to nucleotides 153-185 of the rat GAT-1 GABA transporter gene (Guastella et al., 1990) was synthesized using an automated DNA synthesizer and purified by gel filtration. The probe $(100 \mathrm{ng})$ was $3^{\prime}$ end-labeled to a specific activity of approximately $10^{\circ} \mathrm{cpm} / \mu \mathrm{g}$ by incubation with ${ }^{35} \mathrm{~S}$-dATP $(1000-1500$ $\mathrm{Ci} / \mathrm{mm}$ ol; New England Nuclear NEG $034 \mathrm{H}$ ) and $50 \mathrm{U}$ terminal deoxynucleotidyl transferase (Pharmacia, UK) in tailing buffer at $37^{\circ} \mathrm{C}$ for $30 \mathrm{~min}$. The radiolabelled probe was purified on a Sephadex G-50 column. Brain sections from each experiment were processed simultaneously. Frozen sections were warmed to room temperature with a hair dryer and fixed in $4 \%$ paraformaldehyde $/ 0.1 \mathrm{M}$ phosphate buffer for 20 min. Sections were then rinsed in $0.1 \mathrm{M}$ phosphate buffer saline before being dehydrated through a series of graded ethanols and left to air dry at room temperature. For hybridization, the ${ }^{35} \mathrm{~S}$ labeled probe was diluted in hybridization buffer ( $50 \%$ deionized formamide, $4 \times$ SSC, $10 \%$ dextran sulfate, $1 \times$ Denhardt's solution, $250 \mu \mathrm{g} / \mathrm{ml}$ sheared salmon testis DNA, $0.3 \% \beta$-mercaptoethanol) to a final concentration of approximately $2 \times 10^{3} \mathrm{cpm} / \mu \mathrm{l}$, and $250 \mu \mathrm{l}$ of diluted probe was applied to each slide containing four coronal brain sections. Following an overnight hybridization at $37^{\circ} \mathrm{C}$, sections were rinsed in $1 \times \mathrm{SSC}$ at room temperature $(5 \mathrm{~min})$, three times at $55^{\circ} \mathrm{C}(30 \mathrm{~min}$ each) and then for 1 $\mathrm{hr}$ at room temperature. After a brief rinse in $\mathrm{dH}_{2} \mathrm{O}$ followed by $70 \%$ ethanol $/ 300 \mathrm{~mm}$ ammonium acetate $(30 \mathrm{sec})$ and then absolute alcohol $(30 \mathrm{sec})$, sections were left to air dry before being apposed to Hyperfilm $\beta$-Max (Amersham) for 3 weeks. Slides were then dipped in Ilford K-5 nuclear track emulsion and exposed for 8-10 weeks in light-tight boxes. After developing with Ilford Phenisol $\left(1: 5,5 \mathrm{~min}\right.$ at $\left.20^{\circ} \mathrm{C}\right)$ slides were counterstained lightly with methylene blue and coverslipped. We have reported previously that this oligonucleotide recognizes a single $4.5 \mathrm{~kb}$ band on Northern analysis (Augood et al., 1995) and further assessed specificity of the oligonucleotide in these experiments by use of competition experiments in which the radiolabeled probe was hybridised to sections in the presence of a 25 -fold excess of unlabeled probe.

Experiment 2: effect of $\gamma$-vinyl GABA treatment on GAT-1 mRNA. Two groups of ovariectomized rats were used. The first group $(n=5)$ received a daily subcutaneous injection of the GABA transaminase inhibitor, gamma vinyl GABA (GVG; Vigabatrin; Marion Merrell Dow, U.K.; $150 \mathrm{mg} / \mathrm{kg}$ ), dissolved in $2-300 \mu \mathrm{l}$ of $0.9 \%$ saline for $7 \mathrm{~d}$ while the second group $(n=5)$ received the $0.9 \%$ saline injection alone. Animals were then decapitated between 10:00 and 11:00 hr the following day and their brains cut into two halves in the sagittal plane. The right half was frozen on dry ice and processed for GAT-1 in situ hybridization as detailed above. The left half of the brain was cut so that a coronal block approximately $1.0-1.5 \mathrm{~mm}$ thick containing the anterior commisure (equivalent to plates 19-22 of Swanson, 1992) was obtained and a tissue punch of the preoptic area (diameter $1.0 \mathrm{~mm}$ ) and parietal cortex (diameter $1.5 \mathrm{~mm}$ ) taken. Tissue punches were frozen immediately in Eppendorf tubes and processed for tissue GABA and protein content. Protein analysis was carried out using the Folin-Lowry method and the GABA content determined using reverse phase high-performance liquid chromatography with fluorescence detection as described previously (Herbison et al., 1991).

Experiment 3: effect of estrogen-treatment on ${ }^{3} H-G A B A$ uptake in vitro. Female rats were ovariectomized and 3 weeks later were given subcutaneous silastic capsules containing either sesame oil alone (OVX; $n=6$ ) or sesame oil containing $50 \mu \mathrm{g} / \mathrm{ml} 17 \beta$-estradiol (OVX-E7d; $n$ =6) under Avertin anaesthesia. One week later, between 9:30 and 11: $00 \mathrm{hr}$, rats were decapitated, their brains quickly removed and a complete $3-4 \mathrm{~mm}$ thick coronal brain section containing the preoptic area and hypothalamus glued to a cutting block with cyanoacrylate glue. Brains were then placed in a vibroslice (752M Campden Instruments, UK) culting chamber containing ice cold, artificial cerebrospinal fluid (aCSF; composition in $\mathrm{mM}, \mathrm{NaCl} 124, \mathrm{KCl} 5, \mathrm{KH}_{2} \mathrm{PO} 41.25, \mathrm{NaHCO}_{3}$ $25, \mathrm{MgSO}_{4} 2, \mathrm{CaCl}_{2} 2$, glucose 5) bubbled with $95 \% \mathrm{O}_{2}, 5 \% \mathrm{CO}_{2}$ Coronal sections, $300 \mu \mathrm{m}$ thick, were then cut through the preoptic area and the two sections on either side of the cut bisecting the anterior commissure (plates 19-21, Swanson, 1992) were collected into ice cold aCSF and unilateral punches taken of the medial preoptic area (diameter $1.0 \mathrm{~mm}$ ), caudate-putamen (diameter $1.5 \mathrm{~mm}$ ), and parietal cortex (diameter $1.8 \mathrm{~mm}$ ). The 12 punches obtained from each animal were then placed together in groups of three (one preoptic, one caudate-putamen, one cortex) in four incubation chambers each containing $300 \mu \mathrm{l}$ of gassed aCSF maintained at $37^{\circ} \mathrm{C}$. After $40 \mathrm{~min}$ the aCSF was replaced with $300 \mu \mathrm{l}$ of aCSF containing $50 \mathrm{nM}{ }^{3} \mathrm{H}$ GABA $(86 \mathrm{Ci} / \mathrm{mmol}$; Amersham, UK) and $100 \mu \mathrm{M}$ aminoxyacetic acid (Sigma, UK), the GABAtransaminase inhibitor (Clark et al., 1992), for 10 (chambers 1-3) or 20 (chamber 4) min. For each animal, punches in the first chamber had 1 mM unlabeled GABA included in the ${ }^{3} \mathrm{H}$ GABA-aCSF and served as a control for nonspecific ${ }^{3} \mathrm{H}$ GABA accumulation. Sections in the second chamber were incubated in the ${ }^{3} \mathrm{H}$ GABA-aCSF for $10 \mathrm{~min}$ while 100 $\mu \mathrm{M} \beta$-alanine (Sigma, UK) was included in the ${ }^{3} \mathrm{H}$ GABA-aCSF of the third chamber. In an earlier set of experiments using intact female rats $(n=9)$, the effects of $10 \mu \mathrm{M} \pm$ nipecotic acid (Sigma, UK) on ${ }^{3} \mathrm{H}$ GABA uptake in preoptic, caudate putamen, and parietal cortex punches was examined in a similar manner by including nipecotic acid in the 10 min ${ }^{3} \mathrm{H}$ GABA-aCSF incubation of one chamber but not another. At the end of the ${ }^{3} \mathrm{H}$ GABA incubation period, the tritiated GABA was removed and replaced with ice-cold aCSF. Individual punches were then removed from the wells and placed in Eppendorfs containing aCSF on ice. This aCSF was changed three times with $300 \mu l$ of fresh ice-cold aCSF before being replaced with $300 \mu \mathrm{l}$ of distilled water. At least 30 min later, each Eppendorf was sonicated for $30 \mathrm{sec}$ and centrifuged. The supernatant was removed and placed in a scintillation vial with 4 $\mathrm{ml}$ of Ultima Gold scintillation fluid and counted on a Packard Tricarb $1900 \mathrm{CA}$ counter. Protein analysis of the centrifuged pellet was carried out using the Folin-Lowry procedure.

Data analysis. For in situ hybridization experiments, numbers of silver grains overlying individual cells in the medial and lateral divisions of the medial preoptic nucleus (MPN, plates 20 and 21 of Swanson, 1992), anteroventral periventricular preoptic nucleus (AVPv, plate 19), magnocellular preoptic nucleus (MgPOA; plates 20 and 21 ), caudateputamen (plate 19) and parietal cortex (all layers, plates 20 and 21) were determined using a Leica Orthoplan microscope coupled to a Joyce-Loebl Magiscan analyzer. In each of these regions, 18-25 labeled cells were analysed from both sides of the brain of each animal. Cells within the central nucleus of the MPN were excluded from the analysis as the density of cells in this area precluded us from determining precisely which overlying silver grains were related to which cells. Initially, the number of silver grains overlying cells in the excess unlabelled probe control sections were determined and, in experimental sections, only those cells expressing numbers of silver grains greater than three times that of controls were used for analysis. For each rat and each region an average silver grain count/cell was determined and these values combined to give experimental group means. Earlier experiments in which we coexpressed radioactive standards with hybridized brain sections showed that our detection system exhibited a linear relationship between optical density and radioactivity levels present in the brain sections and that this was not saturated at even the highest level of signal. In the estrogen replacement experiment involving three experi- 
Figure 1. A direct autoradiograph print showing the distribution of GAT-1 mRNA in the coronal plane of an intact metestrous female rat visualized using the ${ }^{35} \mathrm{~S}-\mathrm{GAT}-1$ oligonucleotide and in situ hybridization. A strong signal is noted in the magnocellular preoptic nucleus $(M g-P O A)$, medial and lateral septum and suprachiasmatic nucleus $(S C N)$. Scattered, highly expressing cells are evident throughout the cerebral cortex and striatum as discrete black dots. Overall GAT-1 mRNA expression is less intense within the medial preoptic nucleus $(M P N)$ although relatively high expression is observed in the central division of the MPN (black dot within MPN).

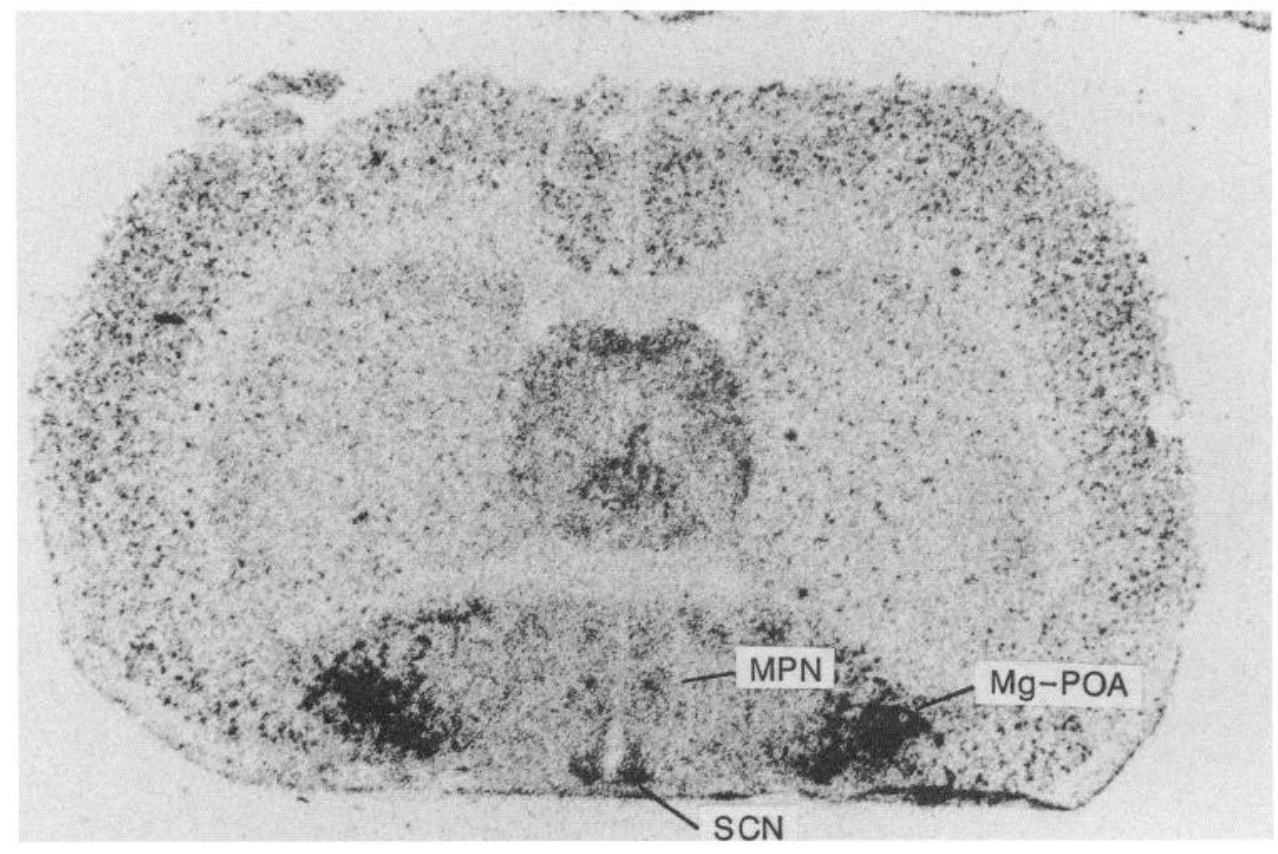

mental groups, statistical analysis was carried using a nonparametric ANOVA followed by the post-hoc Dunn's multiple comparison test. Statistical analysis in other experiments was undertaken with the nonparametric Mann-Whitney $U$ test.

In the ${ }^{3} \mathrm{H}$ GABA uptake studies, the amount of ${ }^{3} \mathrm{H} \mathrm{GABA}$ in each tissue punch, recorded as disintegrations per minute (dpm), was divided by its total protein content to give dpm/ $\mu$ g protein. For each animal the $\mathrm{dpm} / \mu \mathrm{g}$ protein values from punches in the first chamber incubated with excess unlabeled GABA, and reflecting nonspecific ${ }^{3} \mathrm{H}$ GABA incorporation, were subtracted from punch values in the other three parallel chambers to give specific ${ }^{3} \mathrm{H}$ GABA uptake (Boden et al., 1992). Nonparametric statistical analyses were undertaken using ANOVA followed by Dunn's test for comparison between the three different brain regions and paired- or Mann-Whitney $U$ tests for transport inhibitor and OVX versus OVX-E7d comparisons, respectively.

\section{Results}

In situ hybridization for GAT-1 mRNA

The regional distribution of GAT-1 mRNA was observed in coronal brain sections following film (Fig. 1) and emulsion (Fig.
2) autoradiography. Cells expressing GAT-1 transcripts were distributed throughout the coronal brain sections in a heterogeneous manner. The most abundant signal was detected in the magnocellular preoptic area (Mg-POA; Figs. 1, 2A), diagonal band of Broca and both medial and lateral divisions of the septum (Fig. 1). Individual cells displaying relatively high GAT-1 mRNA signal were also detected throughout the cerebral cortex (Fig. 2) and caudate-putamen. Numerous cells expressing a relatively low GAT-1 mRNA signal were found in the preoptic area (Fig. 2) and anterior hypothalamus. Positively hybridized cells were detected in both the medial preoptic nucleus (MPN; Figs. 1, 2) and anteroventral periventricular nucleus (AVPv) of the preoptic area. A strong hybridization signal was noted in the suprachiasmatic nucleus and central division of the MPN (Fig. 1). No signal was detected in sections hybridized in the presence of excess unlabelled GAT-1 probe; the mean number of silver
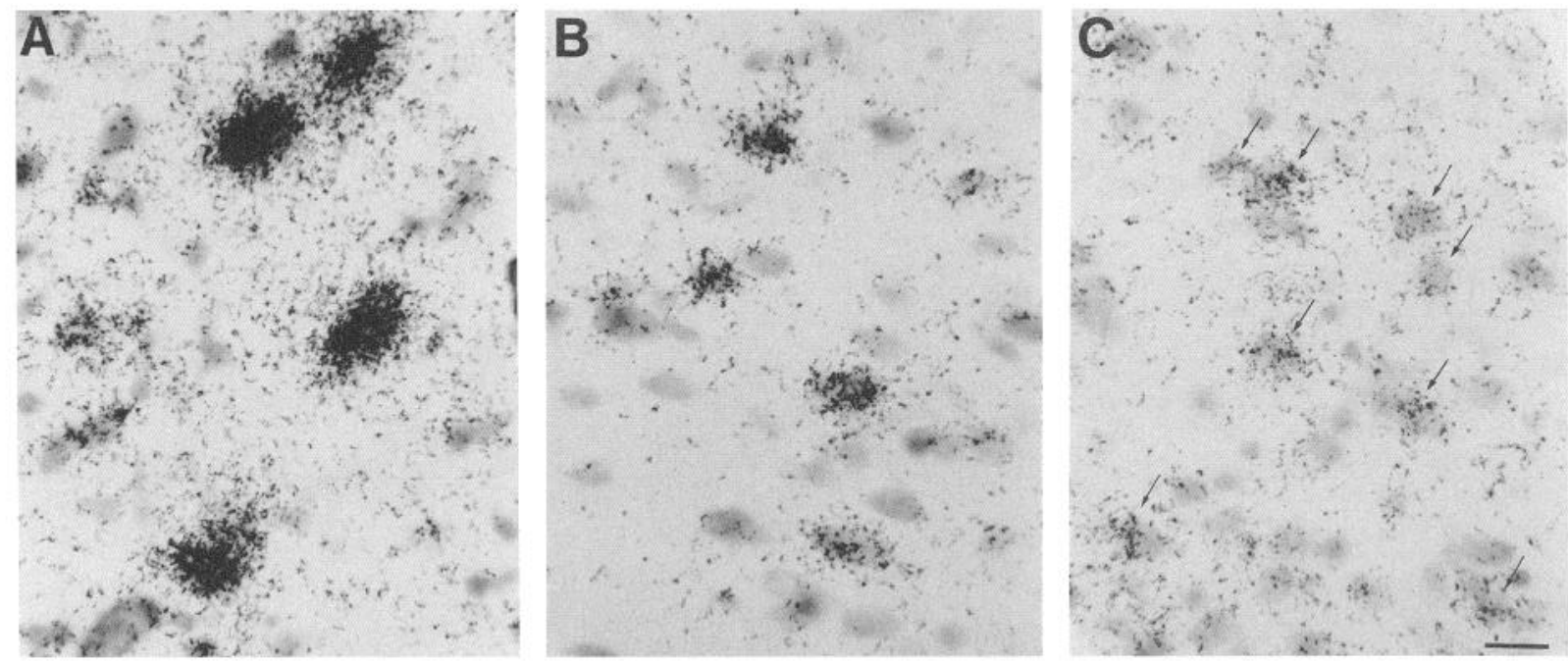

Figure 2. High power photomicrograph of silver grain clusters over individual cells in the magnocellular preoptic nucleus $(A)$, parietal cortex (B), and medial preoptic nucleus $(C)$ of an ovariectomized rat following hybridization with the ${ }^{35} \mathrm{~S}-\mathrm{GAT}-1$ oligonucleotide. Arrows in $C$ indicate individual cells expressing GAT-1 transcripts. All sections have a light counterstain with methylene blue. Scale bar represents $15 \mu \mathrm{m}$ and is the same for $A-C$. 

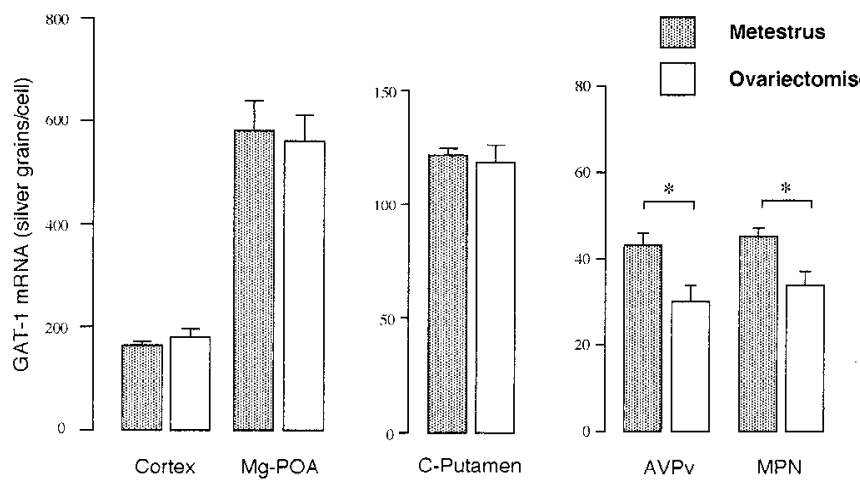

Figure 3. Quantitative analysis of numbers of silver grains/cell reflecting cellular GAT-1 mRNA content in the parietal cortex (Cortex), magnocellular preoptic nucleus $(M g-P O A)$, caudate-putamen (C-Putamen), anteroventral periventricular nucleus $(A V P v)$, and medial preoptic nucleus (MPN) of metestrous (shaded bars) and ovariectomized (open bars) rats. ${ }^{*}, p<0.05$.

grains detected over individual cells $(n=18-25)$ in excess control sections taken from the different GAT-1 mRNA hybridization experiments ranged from 3.6 to 4.8 silver grains/cell. The specificity of this oligonucleotide is demonstrated by (1) its detection of a single $4.5 \mathrm{~Kb}$ band on Northern analysis (Augood et al., 1995), (2) the ability to abolish GAT-1 mRNA signal in a competitive manner with a cold oligo, and (3) the observation that our distribution of GAT-1 mRNA is in good agreement with reports by others (mRNA: Rattray and Priestley, 1993; protein Ikegaki et al., 1994) as well as our own previous work (Augood et al., 1995).

Experiment 1: effect of ovariectomy and estrogen-replacement on GAT-1 mRNA expression

In the first part of this experiment, GAT-1 mRNA expression in the AVPv, MPN, Mg-POA, caudate-putamen, and parietal cortex was examined in OVX and metestrous rats. A significant $(p<$ $0.05)$ 25-30\% decrease in GAT- 1 mRNA signal was detected in the AVPv $(30 \pm 4$ silver grains/cell) and MPN $(34 \pm 3)$ of ovariectomized rats compared with metestrous animals (AVPv, $43 \pm 3$; MPN, $45 \pm 2$ silver grains/cell; Fig. 3). No differences were detected in the Mg-POA, caudate-putamen and parietal cortex (Fig. 3)

In the second part of the experiment the effect of estrogen replacement on GAT-1 mRNA in the MPN and parietal cortex was evaluated in OVX, OVX-E24h and OVX-E7d rats. Within the MPN a significant $39 \%$ increase in GAT-1 mRNA signal was detected following $7 \mathrm{~d}$, but not $24 \mathrm{hr}$, estrogen treatment (OVX, $56 \pm 3$ silver grains/cell; OVX-E24h, $69 \pm 4$; OVXE7d, $78 \pm 8$; ANOVA $p<0.05$, post-hoc Dunn's test $p<0.05$; Fig. 4). No significant difference was detected in GAT-1 mRNA signal within the parietal cortex of the three animal groups (OVX, $186 \pm 17$ silver grains/cell; OVX-E24h, $214 \pm 18$ OVX-E7d, $218 \pm$ 16; Fig. 4).

\section{Experiment 2: effect of $G V G$ treatment on GAT-1 mRNA expression}

As the changes in GAT-1 mRNA content following $7 \mathrm{~d}$ of estrogen treatment may have resulted from direct actions of elevated GABA levels on GAT-1 mRNA content, an experiment was performed to assess the effect of increasing endogenous GABA levels for $7 \mathrm{~d}$ on GAT-1 mRNA expression. Ovariectomized rats receiving the GABA transaminase inhibitor GVG at a
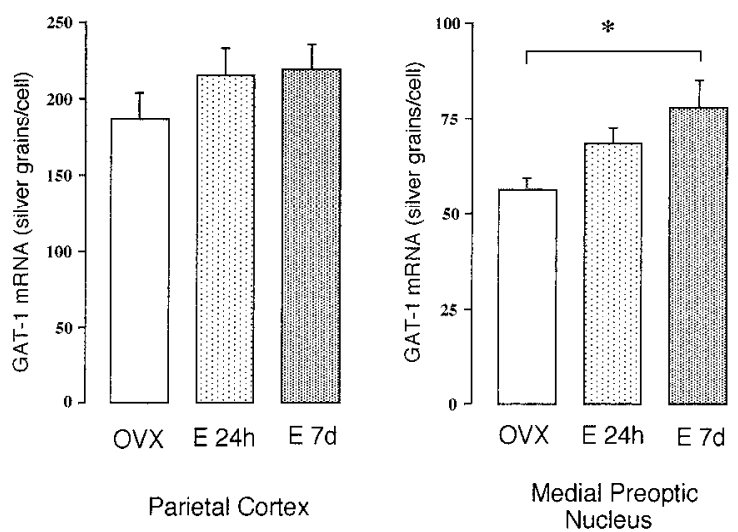

Figure 4. Quantitative analysis of numbers of silver grains/cell reflecting cellular GAT-1 mRNA content in the parietal cortex and medial preoptic nucleus of ovariectomized rats treated with vehicle $(O V X)$ or $17-\beta$ estradiol for $24 \mathrm{hr}(E 24 h)$ or $7 \mathrm{~d}(E 7 D))^{*}, p<0.05$.

concentration of $150 \mathrm{mg} / \mathrm{kg} / \mathrm{d}$ displayed no motor or arousal deficits. The tissue GABA content of preoptic area and parietal cortex punches from the left cerebral hemisphere of GVG-treated animals were two- to threefold greater (preoptic $130 \pm 9$, cortex $80 \pm 7 \mathrm{nmol} \mathrm{GABA} / \mathrm{mg}$ protein) than those of control animals (preoptic $68 \pm 9$, cortex $28 \pm 3 \mathrm{nmol}$ GABA $/ \mathrm{mg}$ protein; $p<0.01$; Fig. 5). In situ hybridization experiments with the GAT-1 mRNA probe using the right hemisphere MPN and parietal cortex of these animals revealed no differences in GAT-1 mRNA expression between the GVG- and saline-treated rats in either brain region (Fig. 5).

\section{Parietal Cortex}
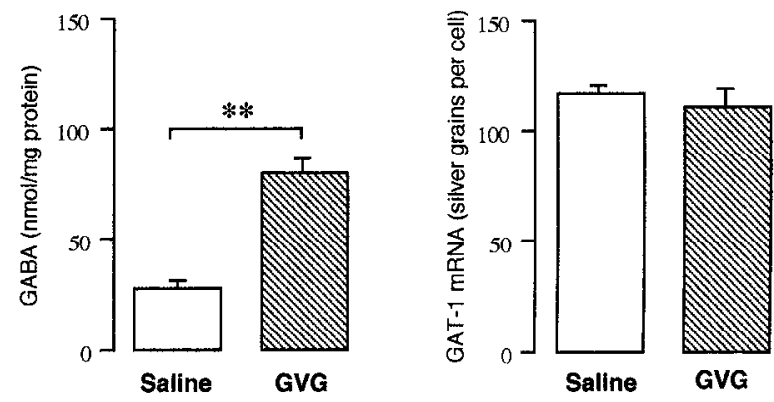

Medial Preoptic Area
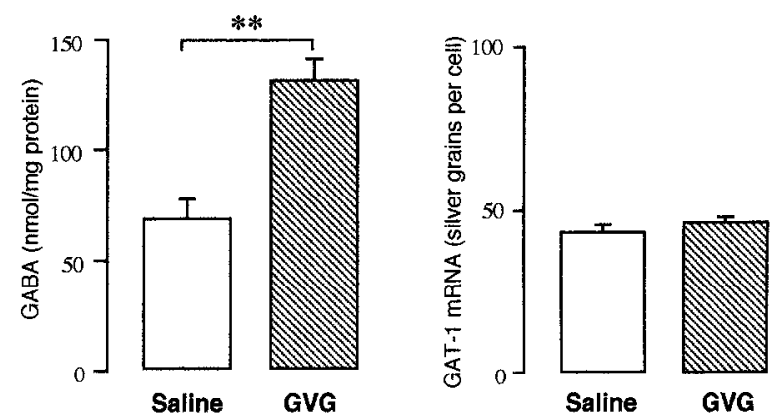

Figure 5. Effect of $\gamma$-vinyl GABA $(G V G)$ treatment on tissue GABA (left) and cellular GAT-1 mRNA (right) content in the parietal cortex and medial preoptic area. Note that GVG treatment increases tissue GABA content by approximately twofold $(* *, p<0.01)$ compared with controls (saline) in both regions but has no effect on GAT-1 mRNA content. 


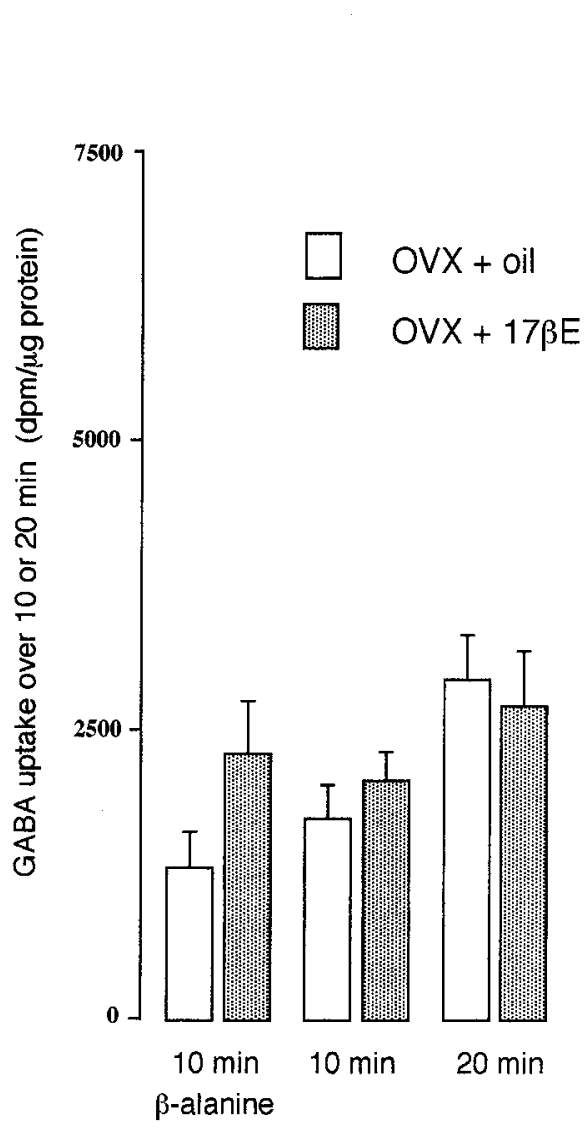

Parietal Cortex

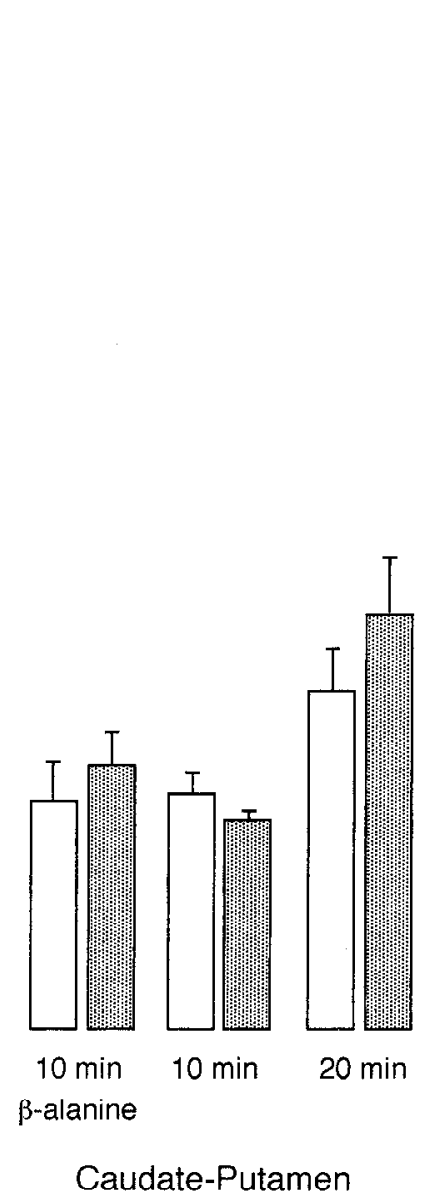

Figure 6. Effect of $7 \mathrm{~d}$ estradiol treatment on specific ${ }^{3} \mathrm{H}$ GABA uptake in parietal cortex, caudate-putamen and medial preoptic area brain slice punches in vitro. Brain punches were incubated with $50 \mathrm{nM}$ 'II GABA for $10 \mathrm{~min}$ (with and without $100 \mu \mathrm{M} \beta$-alanine) or 20 min. Note that estradiol treatment (shaded bars) has no effect on ${ }^{3} \mathrm{H}$ GABA uptake compared with vehicle controls (open bars) in the parietal cortex and caudateputamen, but increases uptake in the medial preoptic area. Significant increases $\left(^{*}, p<0.05\right)$ were observed in the 10 min $+\beta$-alanine, and 20 min incubations. The increase observed in 10 min incubations without $\beta$-alanine failed to reach the $5 \%$ significance level $(p=0.06)$.

Experiment 3: effect of estrogen treatment on ${ }^{3} \mathrm{H}-\mathrm{GABA}$ uptake in vitro

Pharmacological analyses in heterologous expression systems have shown that $10 \mu \mathrm{M}$ nipecotic acid and $100 \mu \mathrm{M} \beta$-alanine are relatively specific inhibitors of GAT-1 (50\% inhibition but only $5-12 \%$ inhibition of GAT-2/3) and GAT-2/3 (70\% inhibition but only $11 \%$ inhibition of GAT-1) transporters, respectively (Borden et al., 1992; Clark et al., 1992). Addition of $10 \mu \mathrm{M}$ nipecotic acid resulted in significant decreases in specific ${ }^{3} \mathrm{H}-$ GABA uptake by all three brain regions (preoptic area, $47 \pm$ $9 \%$ decrease, $p<0.01$; caudate-putamen, $37 \pm 7 \%$ decrease, $p$ $<0.05$; parietal cortex, $21 \pm 6 \%$ decrease, $p<0.05 ; n=8-9$ ). In contrast, $100 \mu \mathrm{M} \beta$-alanine was found to have no significant effect on specific ${ }^{3} \mathrm{H}$ GABA uptake in the parietal cortex or caudate-putamen (Fig. 6). In the preoptic area, $\beta$-alanine reduced ${ }^{3} \mathrm{H}$ GABA uptake by $26 \pm 11 \%$ in OVX rats and by $32 \pm 9 \%$ in $\mathrm{OVX}+\mathrm{E} 7 \mathrm{~d}$ rats, and when combined $(n=12)$, a significant $28 \pm 4 \%$ reduction in ${ }^{3} \mathrm{H} \mathrm{G} \Lambda \mathrm{B} \Lambda$ uptake was observed $(p-$ $0.05)$.

Significant differences in total ${ }^{3} \mathrm{H}-\mathrm{GABA}$ uptake were observed between the three brain regions following either the 10 (ANOVA $p<0.01$ ) or 20 (ANOVA $p<0.001$ ) min incubation in ${ }^{3} \mathrm{H}-\mathrm{GABA}$ (Fig. 6). In all cases, ${ }^{3} \mathrm{H}-\mathrm{GABA}$ uptake $(\mathrm{dpm} / \mu \mathrm{g}$ protein) was significantly greater ( $p<0.05$, Dunn's test) in the medial preoptic area compared with either the parietal cortex or caudate-putamen (Fig. 6). Also, significantly more ${ }^{3} \mathrm{H}-\mathrm{GABA}$ was observed following the 20 min incubation compared with the 10 min exposure in all three brain regions $(p<0.05$ preoptic area; $p<0.01$ caudate-putamen and parietal cortex; Fig. 6). Estrogen treatment for $7 \mathrm{~d}$ had a significant $(p<0.05)$ effect in enhancing specific ${ }^{3} \mathrm{H}-\mathrm{GABA}$ uptake in preoptic punches following the 20 min incubation and 10 min incubation which included $100 \mu \mathrm{M} \beta$-alanine (Fig. 6). A nonsignificant $(p=0.06)$ increase in uptake was observed in the normal 10 min incubation in the preoptic area. Estrogen treatment had no significant effect on specific ${ }^{3} \mathrm{H}-\mathrm{GABA}$ uptake in the parietal cortex or caudate-putamen (Fig. 6).

\section{Discussion}

These results provide evidence for a region-specific regulation of GABA transporter activity by estrogen in the female rat brain. Ovariectomy results in a significant decrease in cellular GAT 1 mRNA content in the medial preoptic area, but not cerebral cortex or caudate-putamen, and expression is returned to normal intact levels by $7 \mathrm{~d}$ estrogen treatment. Correspondingly, we show that ${ }^{3} \mathrm{H}-\mathrm{GABA}$ uptake in vitro is enhanced in the preoptic area but not the other brain regions by the same $7 \mathrm{~d}$ estrogen replacement paradigm. Pharmacological analysis suggests that 
GAT- 1 is active in transporting GABA in all of the brain regions examined while GAT-3 and/or GAT-2 may only be of significance in the preoptic area. The effects of estrogen on GAT-1 mRNA expression in the medial preoptic area are unlikely to be secondary to changes in brain GABA concentrations as 2-fold increases in tissue GABA content are shown to have no effect on GAT-1 mRNA content.

Our in vitro ${ }^{3} \mathrm{H}-\mathrm{GABA}$ uptake studies provide a good functional correlation with the reported distribution of the different GABA transporter subtypes. The medial preoptic area expresses both GAT-1 and GAT-3 transporters while the caudate-putamen and cerebral cortex contain GAT-1 but not GAT-3 (Clark et al., 1992; Ikegaki et al., 1994; Augood et al., 1995). The distribution of cells expressing GAT-2 mRNA in the rat brain has yet to be reported but initial immunocytochemical evidence suggests that GAT-2 may only be expressed by ependymal and arachnoid cells (Ikegaki et al., 1994). We show here that nipecotic acid, at concentrations known to inhibit GAT- 1 by $50 \%$ and GAT-2/3 by less than 12\% (Borden et al., 1992; Clark et al., 1992), significantly reduces ${ }^{3} \mathrm{H}$-GABA uptake in all three brain regions while $\beta$-alanine, at concentrations known to inhibit GAT-2 and 3 by $70 \%$ and GAT-1 by only $11 \%$ (Borden et al., 1992; Clark et al., 1992), was only effective in reducing ${ }^{3} \mathrm{H}-\mathrm{GABA}$ uptake in the preoptic area. Although caution must be taken in extrapolating pharmacological results from heterologous expression systems to brain slices in vitro, it remains that we have found a gond correlation between GAT-3 expression as reported by others (Clark et al., 1992; Ikegaki et al., 1994) and the relative pharmacological specificity of $\beta$-alanine in these three brain regions. In agreement with earlier studies (Hokfelt et al., 1970; Levi et al., 1973) we also note substantial differences in total ${ }^{3} \mathrm{H}-\mathrm{GABA}$ uptake by different brain regions with uptake in the preoptic area being approximately double that of the cerebral cortex and caudate-putamen.

We present here evidence for a regionally selective regulation of GABA transporter function by estrogen in the rat brain. As indicated by previous studies (Clark et al., 1992; Ikegaki et al., 1994) and our pharmacological analysis of GABA transport in vitro, GAT-1 appears to be the most significant of the three GABA transporters identificd so far in determining total GABA transport within the rat preoptic. area, cerebral cortex and caudate-putamen. Our quantitative analysis of cellular GAT-1 mRNA content has shown that the removal of ovarian steroids by ovariectomy reduces GAT-1 mRNA expression by $25-30 \%$ in the MPN and AVPV of the medial preoptic area and that estrogen treatment of ovariectomized rats for $7 \mathrm{~d}$ restores GAT- 1 InRNA content. No effects of ovariectomy or estrogen treatment were detected in the magnocellular preoptic nucleus, parietal cortex, or caudate-putamen. As estrogen receptors are detected in abundance within the preoptic area but not the other brain regions examined in this study (Pfaff and Keiner, 1973; Simerly et al., 1990; Herbison and Theodosis, 1992), one explanation for the regional specificity of estrogen's influence may be that the estrogen receptor is a transcriptional regulator of the GAT-1 gene. We note that a nucleotide sequence GGACAgtcTGACC immediately $3^{\prime}$-prime to the open reading frame of the GAT-1 gene (nucleotides 1946-1959) exhibits only a single base difference compared with the consensus estrogen response element (GGTCAnnnTGACC). Hence, estrogen may regulate GAT-1 gene transcription through the estrogen receptor and the regional specificity of its actions may be dependent upon the absence of estrogen receptors in GABA neurones and glial cells of the ce- rebral cortex and caudate-putamen but their presence in the preoptic area (Flugge et al., 1986; Langub and Watson, 1992; Herbison et al., 1993). Equally, however, there is increasing evidence that intracellular second messenger pathways play an important role in determining GABA transporter function (Clark and Amara, 1993) and actions of estrogen on phosphoinositide and adenylate cyclase pathways have been described (Kow et al., 1994).

Our results provide a good correlation between cellular GAT-1 mRNA content and GABA transporter activity. The in vitro experiments show that estrogen treatment increases total ${ }^{3} \mathrm{H}-\mathrm{GABA}$ uptake in the preoptic area and indicate that the changes in GAT-1 mRNA content of preoptic cells are likely to be translated into functional differences in GABA transport. Interestingly, this increase in uptake, observed in 20 min incubations, was only observed in the $10 \mathrm{~min}$ incubations in the presence of $\beta$-alanine when the majority of GAT- 2 and GAT- 3 transport is inhibited. Although the contribution of GAT-2 and/or GAT-3 to GABA uptake in the preoptic area may be relatively small, the use of $\beta$-alanine to reduce their influence on total GABA uptake enabled us to "unmask" the estrogen dependence of GAT-1 in 10 min incubations. The absence of any effect of estrogen on total ${ }^{3} \mathrm{H}-\mathrm{GABA}$ uptake in the caudate-putamen and parietal cortex is in good agreement with our finding that GAT-1 mRNA is not influenced by ovarian steroid manipulations in these regions.

We hypothesized that changes in GABA transporter function within the medial preoptic area may underly differences in extracellular GABA concentrations observed in ovariectomized and estrogen-treated rats. Our observations are the opposite, however, of what we would have predicted as in vitro GABA transport and GAT- 1 mRNA expression are increased, rather than decreased, at a time when GABA concentrations are relatively high in estrogen-treated rats. As such it was apparent that the increased GABA concentrations in the preoptic area may themselves regulate GAT- 1 and that the changes in mRNA expression may be driven by alterations in endogenous GABA rather than estrogen. Accordingly, we carried out a further experiment to examine whether an increase in endogenous GABA levels achicved through inhibition of GABA transaminase, could influence GAT-1 mRNA expression. As an irreversible inhibitor of GABA-transaminase, GVG has been shown previously to increase GABA concentrations in a variety of brain regions following parenteral administration (Abdul-Ghani et al., 1980; Gale and Iadarola, 1980; Neal and Shah, 1990; Rimvall et al., 1993; Jolkkonen et al., 1994). Such increases in total GABA content are believed to represent elevations in neuronal and glial intracellular compartments as well as increases in extracellular GABA levels (Abdul-Ghani et al., 1980; Gale and Iadarola, 1980; Neal and Shah, 1990). In agreement with others we find that the $150 \mathrm{mg} / \mathrm{kg} / \mathrm{d}$ dose of GVG does not alter behavior (Jolkkonen et al., 1994) and that $150-250 \mathrm{mg} / \mathrm{kg} / \mathrm{d}$ results in a twoto threefold increase in total GABA content within the cerebral cortex as well as elsewhere in the brain (Neal and Shah, 1990; Rimvall et al., 1993; Jolkkonen et al., 1994). This increase in GABA does not, however, influence GAT-1 mRNA expression in either the cerebral cortex or medial preoptic area and our results indicate that increases in intracellular and extracellular GABA levels do not influence GAT-1 mRNA expression.

The mechanism by which estrogen increases basal GABA concentrations in the rat preoptic area remains unresolved. The changes in GABA transporter observed in this study are posi- 
tively correlated with endogenous GABA concentrations making it difficult to reconcile the increased basal GABA concentrations with elevated GABA transporter activity in this brain region. On the other hand, the estrogen-dependent increase in GABA transporter expression within the preoptic area may be responsible for the observed increases in potassium-stimulated GABA release (Herbison et al., 1989, 1991) through electrogenic reversal of the transporter (Fleischmann et al., 1992; Altwell et al., 1993). In terms of the basal GABA concentrations however, it is apparent that estrogen must increase GABA release rates in addition to increasing GABA transport to enable net increases in extracellular GABA concentrations to be detected. Our finding that estrogen also increases the expression of specific $\mathrm{GABA}_{\mathrm{A}}$ receptor subunit $m R N A s$ in the preoptic area (Herbison and $\mathrm{Fe}$ nelon, 1995) raises the likelihood that $\mathrm{GABA}_{\mathrm{A}}$ receptors may also be more abundant at the time we observe increased basal GABA concentrations. This multifaceted upregulation of the preoptic GABA network may be of physiological significance to a variety of behavioral and neuroendocrine mechanisms (Mansky et al., 1982; McCarthy et al., 1991) including the negative feedback actions of estrogen on the neural network controlling luteinizing hormone secretion (Herbison et al., 1991). It remains to be established whether such changes are maintained into the afternoon of proestrus when positive feedback actions of estrogen are observed in concert with a disinhibition of the luteinizing hormone network by GABA (Jarry et al., 1988; Herbison and Dyer, 1991).

\section{References}

Abdul-Ghani A, Coutinho-Netto J, Bradford HF (1980) The action of $\gamma$-vinyl-GABA and $\gamma$-acetylenic-GABA on the resting and stimulated release of GABA in vivo. Brain Res 191:471-481.

Attwell D, Barbour B, Szatkowski M (1993) Nonvesicular release of neurotransmitter. Neuron 11:401-407.

Augood SJ, Herbison AE, Emson PC (1995) Localization of GAT-1 GABA transporter mRNA in rat striatum: cellular coexpression with $\mathrm{GAD}_{67}$ mRNA, $\mathrm{GAD}_{67}$ immunoreactivity, and parvalbumin mRNA. J Neurosci 15:865-874.

Borden LA, Smith KE, Hartig PR, Branchek TA, Weinshank RL (1992) Molecular heterogeneity of the $\gamma$-aminobutyric acid (GABA) transport system. J Biol Chem 267:21098-21104.

Boulant JA, Dean JB (1986) Temperature receptors in the central nervous system. Annu Rev Physiol 48:639-654.

Clark JA, Amara SG (1993) Amino acid neurotransmitter transporters: structure, function, and molecular diversity. Bioessays 15:323-332.

Clark JA, Deutch AY, Gallipoli PZ, Amara SG (1992) Functional expression and CNS distribution of a $\beta$-alanine-sensitive neuronal GABA transporter. Neuron 9:337-348.

Demling J, Fuchs E, Baumert M, Wuttke W (1985) Preoptic catecholamine, GABA, and glutamate release in ovariectomised and ovariectomised estrogen-primed rats utilising a push-pull cannula technique. Neuroendocrinology 41:212-218.

Fleischmann A, Etgen AM, Makman MH (1992) Fstradiol plus progesterone promote glutamate-induced release of $\gamma$-aminobutyric acid from preoptic area synaptosomes. Neuropharmacology 31:799-807.

Flugge G, Oertel WH, Wuttke W (1986) Evidence for estrogen-receptive GABAergic neurons in the preoptic/anterior hypothalamic area of the rat brain. Neuroendocrinology $43: 1-5$.

Freeman ME (1994) The neuroendocrine control of the ovarian cycle in the rat. In: The physiology of reproduction (Knobil E, Neill JD, eds), pp 613-658. New York: Raven.

Gale K, Iadarola MJ (1980) Seizure protection and increased nerveterminal GABA: delayed effects of GABA transaminase inhibition. Science 208:288-291.

Guastella J, Nelson N, Nelson H, Czyzyk L; Keynan S, Miedel MC, Davidson N, Lester HA, Kanner BI (1990) Cloning and expression of a rat brain GABA transporter. Science 249:1303-1306.

Herbison AE, Dyer RG (1991) Effect on luteinizing hormone secretion of GABA receptor modulation in the medial preoptic area at the time of proestrous luteinising hormone surge. Neuroendocrinology 53: $317-320$

Herbison AE, Fenelon VS (1995) Estrogen regulation of $\mathrm{GABA}_{\wedge}$ receptor subunit mRNA expression in preoptic area and bed nucleus of the stria terminalis of female rat brain. J Neurosci 15:2328-2337

Herbison AE, Theodosis DT (1992) Localisation of oestrogen receptors in preoptic neurons containing neurotensin but not tyrosine hydroxylase, cholecystokinin or luteinizing hormone-releasing hormone in the male and female rat. Neuroscience 50:283-298.

Herbison AE, Heavens RP, Dyer RG (1989) Oestrogen and noradrenaline modulate endogenous GABA release from slices of the rat medial preoptic area. Brain Res 486:195-200.

Herbison AE, Heavens RP, Dye S, Dyer RG (1991) Acute action of oestrogen on medial preoptic $\gamma$-aminobuyric acid neurons: correlation with oestrogen negative feedback on luteinizing hormone secretion. J Neuroendocrinol 3:101-106.

Herbison AE, Augood SJ, McGowan EM (1992) Expression of glutamic acid decarboxylase messenger RNA in rat medial preoptic area neurones during the oestrous cycle and after ovariectomy. Mol Brain Res 14:310-316.

Herbison AE, Robinson JE, Skinner DC (1993) Distribution of estrogen receptor-immunoreactive cells in the preoptic area of the ewe: co-localization with glutamic acid decarboxylase but not luteinizing hormone-releasing hormone. Neuroendocrinology 57:751-759.

Hokfelt T, Jonsson G, Ljungdahl A (1970) Regional uptake and subcellular localization of $\left({ }^{3} \mathrm{H}\right)-\gamma$-aminobutyric acid (GABA) in rat brain slices. Life Sci 9:203-212.

Ikegaki N, Saito N, Hashima M, Tanaka C (1994) Production of specific antibodies against GABA transporter subtypes (GAT1, GAT2, GAT3) and theit application to immunocytochemistry. Mol Brain Res 26:47-54.

Jarry H, Perschl A, Wuttke W (1988) Further evidence that preoptic anterior hypothalamic GABAergic neurons are part of the GnRH pulse and surge generator. Acta Endocrinol 118:573-579.

Jolkkonen J, Jenner P, Marsden CD (1994) GABAergic modulation of striatal peptide expression in rats and the alterations induced by dopamine antagonist treatment. Neurosci Lett 180:273-276.

Jones KJ, McEwen BS, Pfaff DW (1988) Quantitative assessment of early and discontinuous estradiol-induced effects on ventromedial hypothalamic and preoptic arca proteins in femalc rat brain. Neuroendocrinology 48:561-568

Kow L, Mobbs CV, Pfaff DW (1994) Roles of second-messenger systems and neuronal activity in the regulation of lordosis by neurotransmitters, neuropeptides, and estrogen: a review. Neurosci Biobehav Rev 18:251-268.

Langub MC, Watson RE (1992) Estrogen receptor-immunoreactive glia, endothelia, and ependyma in guinea pig preoptic area and median eminence: electron microscopy. Endocrinology 130:364-372.

Leipheimer RE, Bona-Gallo A, Gallo RV (1984) The influence of progesterone and estradiol on the acute changes in pulsatile luteinizing hormone release induced by ovariectomy on diestrus day 1 in the rat. Endocrinology 114:1605-1613.

Levi G, Bertollini A, Chen J, Raiteri M (1973) Regional differences in the symaptosomal uplake of ${ }^{3} \mathrm{H}$ - $\gamma$-aminobutyric acid and ${ }^{14} \mathrm{C}$-glutamate and possible role of exchange processes. J Pharmacol Exp Ther 188:429-438.

Mansky T, Mestres-Ventura P, Wuttke W (1982) Involvement of GABA in the feedback action of estradiol on gonadotropin and prolactin release: hypothalamic GABA and catecholamine turnover rates. Brain Res 231:353-364.

McCarthy MM, Masters DB, Fiber JM, Lopez-Colome A-M, Beyer C, Komisaruk BR, Feder HH (1991) GABAergic control of receptivity in the female rat. Neuroendocrinology 53:473-479.

McCarthy MM, Kaufman LC, Brooks PJ, Pfaff DW, Schwartz-Giblin S (1995) Estrogen modulation of mRNA for two forms of glutamic acid decarboxylase (GAD) in rat brain. J Comp Neurol, in press.

McGinty D, Szymusiak R, Thomson D (1994) Preoptic/anterior hypothalamic warming increases EEG delta frequency activity within non-rapid eye movement sleep. Brain Res 667:273-277.

Neal MJ, Shah MA (1990) Development of tolerance to the effects of vigabatrin ( $\gamma$-vinyl-GABA) on GABA release from rat cerebral cortex, spinal cord and retina. Br J Pharmacol 100:324-328.

Numan M (1994) Maternal behavior. In: The physiology of reproduction (Knobil E, Neill JD eds), pp 221-284. New York: Raven.

O'Connor LH, Nock B, McEwen BS (1988) Regional specificity of 
$\gamma$-aminobutyric acid receptor regulation by estradiol. Neuroendocrinology 47:473-481.

Ondo J, Mansky T, Wuttke W (1982) In vivo GABA release from the medial preoptic area of diestrous and ovariectomized rats. Exp Brain Res 46:69-72.

Petersen SL, Barraclough CA (1989) Suppression of spontaneous LH surges in estrogen-treated ovariectomized rats by microimplants of antiestrogens into the preoptic brain. Brain Res 484:279-289.

Pfaff D, Keiner M (1973) Atlas of estradiol-concentrating cells in the central nervous system of the female rat. J Comp Neurol 151:121158

Pfaff DW, Schwartz-Giblin S, McCarthy MM, Kow L (1994) Cellular and molecular mechanisms of female reproductive behaviors. In: The physiology of reproduction (Knobil E, Neill JD, eds), pp 107-220. New York: Raven.

Radian R, Ottersen OP, Storm-Mathisen J, Castel M, Kanner B (1990) Immunocytochemical localization of the GABA transporter in rat brain. J Neurosci 10:1319-1330.

Rattray M, Priestley JV (1993) Differential expression of GABA transporter-1 messenger RNA in subpopulations of GABA neurones. Neurosci Lett 156:163-166.
Riıivall K, Sheikh SN, Martin DL (1993) Effects of increased $\gamma$-aminobutyric acid levels on $\mathrm{GAD}_{67}$ protein and mRNA levels in rat cerebral cortex. J Neurochem 60:714-720.

Sar M (1988) Distribution of progestin-concentrating cells in rat brain; colocalization of $\left[{ }^{3} \mathrm{H}\right]$ ORG.2058, a synthetic progestin, and antibodies to tyrosine hydroxylase in hypothalamus by combined autoradiography and immunocytochemistry. Endocrinology 123:1110-1118.

Simerly RB, Chang C, Muramatsu M, Swanson LW (1990) Distribution of androgen and estrogen receptor mRNA-containing cells in the rat brain: an in situ hybridization study. J Comp Neurol 294:76-95.

Swanson LW (1992) Brain maps; structure of the rat brain. Amsterdam: Elsevier.

Wallis CJ, Luttge WG (1980) Influence of estrogen and progesterone on glutamic acid decarboxylase activity in discrete regions of brain. J Neurochem 34:609-613.

Weiland NG (1992) Glutamic acid decarboxylase messenger ribonucleic acid is regulated by estradiol and progesterone in the hippocampus. Endocrinology 131:2697-2702

Yagi K (1973) Changes in firing rates of single preoptic and hypothalamic units following an intravenous administration of estrogen in the castrated female rat. Brain Res 53:343-352. 